\title{
O modelo chinês: um estudo da política de telecomunicações
}

Jawdat Abu-El-Haj

Resumo: O artigo recorre à política das telecomunicações da China para compreender sua ascensão mundial. Mostra que a doutrina de intervenção do Estado, após 1949, permaneceu como seu esteio, apesar da nova organização empresarial e abertura aos capitais externos. Esta doutrina exigiu o direcionamento de recursos institucionais, financeiros, tecnológicos e infraestruturais para criar condições iguais de acesso da população rural e urbana e dos estratos sociais de maior e menor renda.

Palavras-chave: Política de Telecomunicações; Internacionalização do Capital; China.

\section{Jawdat Abu-El-Haj}

Professor do Programa de Pós-Graduação em Sociologia da Universidade Federal do Ceará.

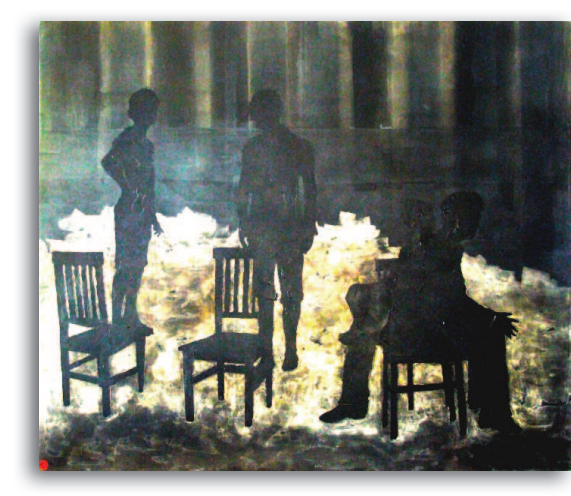

The Chinese model: a study of telecommunication policy

Abstract: The article refers to the telecommunications policy of China to understand its global rise. It shows that the doctrine of state intervention after 1949 remained as its mainstay, despite the new business organization and openness to foreign capital. This doctrine required that institutional, financial, technological and infrastructure resources be directed to create equal conditions of access for rural and urban populations and high and low income social strata.

Keywords: Telecommunications Policy; Internationalization of Capital, China. 


\section{INTRODUÇÃO}

A última década revelou uma súbita ascensão da China à posição de segunda maior potência mundial. Na primeira avaliação, a decolagem chinesa foi atribuída à demografia, afirmando ser normal uma vertiginosa expansão econômica inicial nas transições urbanas. O crescimento intensificou-se fora a noção de pôr uma intervenção planejada do Estado, ao aglutinar e direcionar vultosos recursos financeiros para metas de longo prazo. No entanto, os intérpretes alertavam que o alto desempenho seria temporário. Estados autoritários com poderes para direcionar mercados, inevitavelmente, se degeneram em favoritismo político e corrupção, bloqueando inovações empresariais necessárias para formar complexos nichos industriais e de serviços. Consequentemente, a primeira gloriosa decolagem é seguida por permanente estagnação, apenas remediada por adesão à economia do mercado.

Essa tese popularizada por Chalmers Johnson (1982; 1987), na década de 1980, sobre a meteórica expansão e declínio do Japão, aparentemente, não se confirmou no caso chinês. Dados recentes mostram um crescimento econômico paralelamente à expansão do consumo per capita, melhorias na infraestrutura e desempenho tecnológico remanescente dos países desenvolvidos. Por exemplo, ao mesmo tempo em que,no período entre 1990 e 2010, a média anual de crescimento econômico alcançou 15\%, a expansão da Power Purchasing Parity (PPP), poder aquisitivo per capita, foi de 10\%. O desempenho quantitativo foi complementado por avanços qualitativos. Apesar de o relatório da World Intellectual Property Organization (WIPO), Organização Mundial da Propriedade Intelectual, de 2010, documentar a permanência dos EUA na liderança de registros de patentes com $27,5 \%$ do total mundial, seguidos pelo Japão, com 19,7\%, e a Alemanha com 10,5\%, pela primeira a China assumiu a quarta posição, registrando 7,6\% das patentes mundiais. O aperfeiçoamento tecnológico chinês não é um fenômeno temporário, tenderá a crescer nos anos seguintes, porquanto dois dos seus produtores de telequipamentos, a ZTE e a Huawei, ocupam, no mundo, a segunda e a quarta posições, ultrapassando a sueca Ericsson $\left(9^{\circ}\right)$, maior produtor mundial de telequipamentos, e a japonesa NEC $\left(10^{\circ}\right)$. Ressaltava ainda a Qualcomm, tida como 
a mais agressiva empresa estadunidense de pesquisas de ponta e inventora do CDMA, líder nas pesquisas da Longe Term Evolution (LTE), 4G da banda larga móvel, na terceira colocação, atrás da ZTE.

A primeira tentativa de reinterpretação do caso chinês veio de David Harvey (2005), no final da década de 1990. O êxito seria fruto de uma evolução gradual e planejada rumo à economia de livre mercado, iniciada nos meados da década de 1990 após o ingresso na Organização Mundial do Comércio (OMC) em 1999 e a abertura aos investimentos e comércio externos. Recentemente, dois analistas complementaram essa tese. Gereffi (2009) indicou o ingresso maciço de investidores internacionais como a variável determinante da transferência, adaptação e complexidade industrial. Os efeitos benéficos das multinacionais se revelaram entre 1997 e 2004, quando seus centros de pesquisa se multiplicaram de 50 para 600. Para Gereffi, apesar da permanência do Estado autoritário, o capital internacional induziu o milagre chinês.

A interpretação de Rodrik (2010) associou o êxito à política de promoção das exportações. Dois mecanismos da redução do custo final da produção interna, o câmbio subvalorizado e flexíveis mercados de trabalho, renderam volumosos saldos comerciais que financiaram o crescimento econômico, o refinamento da qualidade e os avanços da produtividade. A globalização demandou das empresas chinesas novos produtos e serviços; comando tecnológico e conhecimentos industriais; e branding, criação de marcas de excelência reconhecidas mundialmente (ILLE; CHAILAN, 2011).

Duas hipóteses permearam as interpretações de Harvey e seus seguidores. Enquanto a primeira atribuiu o desempenho às virtudes do mercado, fruto do rompimento com o passado socialista, a segunda apontou a interdependência global da China, por intermédio do ingresso de multinacionais e da exportabilidade, como fontes de crescimento econômico e dos saltos qualitativos na produtividade, na qualidade e na tecnologia.

No entanto, as teses centradas no mercado não se sustentam perante alguns fatos. Primeiro, apesar de o México ter um estoque de Investimentos Estrangeiros Diretos (IED) equivalente ao da China, seu desempenho não se iguala na qualidade industrial, na complexidade setorial, nos saldos comerciais e na tecnologia. 
Segundo, os produtores chineses atuam tanto em mercados menos desenvolvidos como nos nichos mais disputados na Europa e nos EUA. É improvável que a simplicidade da reverse engineering, tida como plágio técnico, fosse suficiente para estruturar dinâmicos e flexíveis complexos empresariais em setores tecnológicos, tais como aeroespacial, telequipamentos, eletrônicas e automobilística, capazes de desenhar uma multiplicidade de produtos e serviços destinados a mercados diferenciados. Terceiro, a despeito da ativa presença internacional, a parcela maior do retorno financeiro das empresas chinesas seria sua fonte no mercado interno.

Para preencher essas lacunas, o estudo opta por uma análise concreta das telecomunicações, considerado o meio principal da aglutinação de recursos disponíveis para Estados nacionais. Além da eficácia de circulação de comunicações, o grau do comando tecnológico de sistemas e da indústria de telequipamentos prevê uma futura liderança da nova sociedade de informação. A escolha desse setor ainda é reforçada pelo fato de a China ter passado, em menos de uma década, a despontar com ampla cobertura infraestrutural, diversidade de serviços e refinamento tecnológico e industrial. Na próxima década, os sistemas chineses da Next Generation Network (NGN), tanto de banda larga fixa (EPON) como de móvel Time Division-Long Term Evolution (TD-LTE), serão os dois mais difundidos padrões globais adotados pela International Telecommunications Union (ITU).

Dessas circunstâncias surgem algumas indagações.

1) Como a China alcançou um comando de setores de ponta num curto prazo, com gastos financeiros menores do que os países desenvolvidos, tendo limitada estrutura universitária e acesso restrito à ciência de ponta comandada pelos países desenvolvidos?

2) Qual foi a arena determinante da produtividade da empresa chinesa - as exportações ou inserção no mercado interno?

3) A China é um copiador (ou plagiador) de tecnologias (reverse engineering), apoiado por ilimitado crédito financeiro e reservas do mercado, ou é um país inovador e criador de conceitos? 
As origens: o setor público e o equilíbrio interno

A nova organização empresarial dos serviços e da indústria de telequipamentos não significava um rompimento com os princípios da intervenção governamental lançados pela revolução de 1949, mas uma modificação dos seus instrumentos de ação. Desde 1949, o primeiro princípio da intervenção estatal submetia os recursos institucionais, financeiros, tecnológicos e infraestruturais à meta de criar condições iguais de acesso entre o campo e a cidade, as regiões mais desenvolvidas e menos desenvolvidas e os estratos sociais de maior e menor renda. Nas telecomunicações, essa doutrina transformou-se em três práticas embutidas na estrutura organizacional dos dois ministérios responsáveis pelo setor, o Ministry of Posts and Telecommunications (MPT) e o Ministry of Machines Building (MMB), fundados logo após a revolução, em novembro de 1949. Uma divisão de trabalho separava os dois ministérios, instigando frequentes rivalidades por prestígio científico e profissional. Enquanto o MPT, maior e com orçamento superior, se responsabilizava pela engenharia, infraestrutura e equipamentos de interligação, o MMB, controlador dos mais importantes laboratórios de pesquisa, produzia centrais de comutação.

O segundo princípio equiparou o comando da ciência e tecnologia à autodeterminação nacional. Estabelecido no histórico LongTerm Development Plans of S\&T, 1956-1967, primeiro dos oito planos lançados entre 1956 e 2010, por uma comissão formada por centenas de cientistas chineses e os dezesseis mais renomeados pesquisadores soviéticos, e numerou doze prioridades, sendo o polo eletrônico e de telequipamentos o segundo em importância depois da energia nuclear. O primeiro plano, além de fundar marcos acadêmicos, tais como a Academia Chinesa de Ciência, criou um centro especializado em pesquisas e treinamento setorial, China Academy of Posts and Telecommunications, posteriormente, Chinese Academy of Telecommunications Technology.

Direcionar os recursos públicos financeiros, científicos, industriais e infraestruturais aos investimentos rurais compôs o terceiro princípio da intervenção pública. Em 1960, a primeira central de comutação produzida por uma fábrica chinesa, Beijings Wire Communciations Plant do MMB, foi destinada primordialmente 
às regiões rurais. Os dados do MPT revelam uma decisão política para equiparar as redes rurais de comunicações com as metropolitanas. Entre 1949 e 1960, o aumento de centrais telefônicas, de 312 mil para 2,4 milhões, foi mais evidente no campo do que nos grandes centros urbanos. Enquanto a expansão urbana triplicou o número em operação, o aumento na zona rural chegou a 1000\%.

O rompimento com a extinta União Soviética, em 1960, ressaltou mais ainda a determinação chinesa de desenvolver a autonomia tecnológica sustentada por potencialidades internas. Duas tendências se chocavam, a pragmática esboçada por Zhou Enlai, e a linha dura, inspiradora da revolução cultural. Enquanto a primeira defendia a abertura científica, a linha dura clamava por autossuficiência autárquica. A derrota política da linha dura, no final da década de 1970, consagrou Deng Xaoping, seguidor de Zhou Enlai, como o novo líder. Sua política de portas abertas (Open Door Policy) demandava uma transição dos típicos planos quinquenais do aumento quantitativo da produção, praticados desde 1949, para uma nova política da promoção de produtividade e qualidade industrial.

Consequentemente, a década de 1980 iniciou-se com uma brusca abertura para as multinacionais. Começou um intervalo de troca de acesso das multinacionais ao mercado interno por transferência de tecnologia para clusters industriais distribuídos de forma equilibrada entre as diversas regiões: Wenzhou (acendedores de cigarros e calçados), Chenghai (brinquedos) Shenzhen (brinquedos e ornamentos natalinos), Shengzhou (gravatas) e Xinjiang and Dongguan (calçados) (WANG; HONG, 2009).

A linha pragmática de Xaoping poderia ter levado a uma situação de dependência associada: o destino da maioria dos países em desenvolvimento. A abertura indiscriminada da infraestrutura, bem como dos serviços às multinacionais, frequentemente, internacionaliza o mercado interno. Tanto sistemas de comunicações como de telequipamentos, transformados em padrões internos dominantes, refletiam prioridades tecnológicas e financeiras dos investidores externos.

Para evitar o destino dos países em desenvolvimento, o governo chinês planejou a abertura em três etapas. Enquanto abria o 
mercado para joint ventures multinacionais, incentivava produtores de equipamentos locais a adaptarem as tecnologias às regiões rurais e pequenos municípios. Experimentação em regiões inóspitas permitia uma gradual transformação e comando da tecnologia de ponta. Progressivamente, as empresas locais alcançaram uma produtividade equivalente às multinacionais. A segunda etapa, no fim da década de 1990, coincidiu com o acordo da OMC. Então, os departamentos administrativos dos serviços de telecomunicações foram autonomizados em empresas estatais, cobrindo todo o território chinês e introduzindo uma diversidade de sistemas tecnológicos. Nesse contexto, as compras governamentais pelas novas estatais serviram como alimentadores financeiros da indústria de telequipamentos. Quando as experiências e os recursos adquiridos no mercado interno se transformaram em plataformas de exportação, inicialmente para os países menos desenvolvidos (África e Sul asiático) e posteriormente para os nichos mais disputados do mercado internacional, tanto provedores de serviços como produtores de telequipamentos superaram a dependência tecnológica, transitando para inovações próprias como Original Equipment Manufacturer (OEM), empresas com patentes próprias registradas na WIPO. Na terceira etapa, datada de 2008, uma reforma administrativa focada no aumento de investimentos financeiros em ciência e tecnologia foi acompanhada por fusões internas (YU; YIFEI; WEIZ; LIN, 2011). A aglutinação de recursos empresariais, financeiros e tecnológicos impeliu a China para a liderança mundial das telecomunicações. Surgiram três dos principais provedores mundiais de serviços, a segunda e quinta maiores empresas de telequipamentos, e a mais ampla cobertura mundial de fibra óptica. A liderança chinesa do setor de ponta da sociedade do futuro foi uma obra de planejamento governamental direcionada para oferecer condições iguais para seus cidadãos.

\section{TRANSFERÊNCIA, ADAPTAÇÃO E INOVAÇÕES TECNOLÓGICAS NAS REGIÕES RURAIS: A ZTE E A HUAWEI NA LIDERANÇA MUNDIAL}

A política industrial começou em 1982, quando o MPT reuniu suas 27 fabricantes de telequipamentos sob o comando de um novo conglomerado, designado de Posts e Telecommunications 
Industry Corporation (PTIC), com a missão de modernizar a indústria de telequipamentos. Paralelamente, o Ministry of Machine Building (MMB) - Ministério da Construção de Equipamentos, mudou sua designação para Ministry of Electronics Industry (Ministério da Indústria Eletrônica), uma referência à centralidade dada pelo governo sobre a tecnologia da informação. Igualmente ao MPT, suas instalações industriais foram reunidas sob a Beijing Wire Communications Plant e transformadas numa autônoma empresa estatal. Após a reorganização dos dois ministérios, o governo decretou o fim da reserva do mercado, e liberou a importação e o ingresso das multinacionais.

Em 1983, começou a prática de trocar acesso por tecnologia, quando a divisão belga da ITT Corporation formou um joint venture, a Shanghai Bell, com a PTIC, tendo apoio financeiro do Fundo de Desenvolvimento Empresarial (Fund for Development Corporation) do governo belga. Enquanto o PTIC contribuiu com 60\% do capital inicial, coube 31,65\% à ITT e 8,35\% ao governo belga. Como contrapartida, a empresa receberia a preferência do MPT para expandir e modernizar sua rede de telefonia fixa. Para tornar a produção local mais resistente perante os importados, o governo complementou as compras governamentais por meio de uma linha especial de crédito. Em menos de um ano, a Shanghai Bell (agora controlada por Alcatel, a nova proprietária da ITT belga) havia assumido $11 \%$ do mercado chinês. Como o atrativo mercado chinês estava liberado para os importados dos equipamentos de teleinformática, a Shanghai Bell foi obrigada novamente a expandir sua cadeia produtiva, instalando a Shanghai Belling, fábrica especializada em circuitos integrados. Ainda, para reduzir seus custos de produção, subcontratava peças de fornecedores locais, e, assim, elevou, entre 1988 e 1995, o índice de nacionalização de $20 \%$ para $68 \%$.

Em 1988, o segundo empreendimento, lançado pelo Beijing Wire Communications Plant (braço fabril do Ministry of Electronics Industry) com a Siemens, fundou a Beijing International Switching Company (BISC). A empresa alemã controlaria 40\% das ações, sendo o restante de investidores estatais: Beijing Telecommunications Authority (BTA) - Autoridade das Telecomunicações de Beijing, 
Beijing Wire Communications Plant e a empresa municipal Beijing Comprehensive Investment Corporation. Ao lançar mais um empreendimento apoiado por fundos públicos, o governo evitava o monopólio do mercado interno pela Shanghai Bell e, consequentemente, o estancamento da transferência de tecnologia.

Após a instalação de joint ventures com dois dos mais importantes produtores de telequipamentos, Alcatel e Siemens, o Directive 56 do Conselho do Estado (equivalente a Medida Provisória), publicado em 1989, decretou o fechamento do mercado interno para novos investimentos externos. A decisão anuncia ainda a intenção do governo de incentivar o lançamento de empresas locais de telequipamentos, reafirmando o princípio do comando tecnológico com pilar central na autonomia nacional.

Logo após o fechamento, surgiu a primeira empresa chinesa do gênero, a Great Dragon (Julong). Concebida pelo professor de Engenharia de Informação da Zhengzhou College of Information Engineering em Henan, instituição militar de ensino superior e financiada pelo PTIC, declarou no seu estatuto a intenção de assumir a liderança do mercado interno. Em 1991, Great Dragon introduziu sua primeira central de comutação (HJD-04) com compras garantidas pelo MPT e MEI. Por volta de 1994, seus sistemas abasteciam 10\% da demanda interna. Para expandir sua produção, o governo colocou sob seu comando oito fabricantes estatais, quatro do MPT, três do MEI e uma do PLA (exército chinês). Ainda recebeu uma linha especial de crédito para financiar pesquisas e expansão da produção. Após a fusão com o complexo industrial estatal, a Great Dragon se instalou no mesmo complexo empresarial da Beijing Wire Communication Plant, segundo maior produtor e joint venture da Siemens, transmitindo a intenção de assumir a segunda posição no mercado interno e, eventualmente, a liderança absoluta em substituição à francesa Shanghai Bell.

A acirrada competição entre os joint ventures multinacionais, alimentada pela expansão qualitativa e quantitativa dos fornecedores locais e acrescida por avanços tecnológicos e industriais, levava a uma queda vertiginosa de preços das centrais de comutação. Enquanto, em 1994, a unidade comercializada pela Shanghai Bell era em torno de US\$100, em 1999, o valor do mesmo produto 
havia despencado para US $\$ 24$. Incapaz de competir com as multinacionais, a Great Dragon demandou proteção do Estado apoiando-se num tradicional discurso nacionalista.

Dois motivos explicam a recusa do governo chinês em se submeter à pressão da Great Dragon. Primeiro, privilegiar politicamente produtores locais seria um rompimento de contratos e compromissos com investidores internacionais presentes em setores cruciais, a exemplo da indústria automobilística. Segundo, a inabilidade de acompanhar a qualidade e produtividade das multinacionais era uma situação peculiar à Great Dragon. No mesmo período, dois outros produtores locais, a estatal ZTE e a particular Huawei, demonstravam sinais de vigor e desempenho à altura das mais adiantadas empresas mundiais. Por volta de 2002, o fundador da Great Dragon, o professor Wu Jiangxing, pediu demissão. Seu desaparecimento em 2005 anunciava o definitivo fim do paternalismo estatal do antigo regime. Em seu lugar consolidou-se uma nova política industrial, transformando duas indústrias locais nos dois mais dinâmicos gigantes mundiais da hi-tech. O desempenho dos dois grupos foi determinado pela prioridade dada às regiões rurais inóspitas e de baixa renda, nichos do mercado interno distantes das ambições de lucro dos investidores externos (XIE; WHITE, 2006).

Nascida do Ministry of Airspace Industry (MAI) - Ministério da Indústria Aeroespacial, a ZTE começou, em 1985, com a produção de semicondutores. No final da década de 1980, o MPT requisitou a esta empresa uma mudança de foco para telequipamentos com o objetivo de substituir os importados, bem como diminuir o domínio quase monopolista da Shanghai Bell. A aprovação da sua primeira central de comutação (ZX500) pelo MPT parecia uma repetição da malograda política industrial tradicional, adotada no caso da Great Dragon. Contudo, tanto o MPT como a ZTE haviam aprendido com o fracasso anterior. Para poder alcançar qualidade, comandar conhecimento e produzir equipamentos com preços compatíveis com o mercado internacional, a ZTE foi organizada como empresa autônoma para captar recursos financeiros, descentralizar a produção e formar alianças externas e internas. No primeiro ato como estatal, a ZTE fundou seus principais laboratórios de P\&D 
(Pesquisa e Desenvolvimento) em Shanghai e Nanjing e em 1997 adquiriu uma autonomia financeira dos dois ministérios ao vender ações na Shenzhen Exchange.

Entretanto, a autonomia empresarial não teria surtido os efeitos esperados se não existisse uma política industrial destinada ao complexo eletrônico. No anúncio da "National Industrial Policy Outline for the 1990s", em 1994, o setor assumiu o carro chefe da ciência e tecnologia, apoiado por três programas complementares de pesquisas nas ciências básicas (National Basic Research Program), nos estudos tecnológicos avançados (National Advanced Research Program) e nas ciências aplicadas (National Program for Key Science and Technology Development). Produzir equipamentos para o mercado interno, e principalmente para as regiões menos desenvolvidas, definiu a razão inicial de existência da ZTE. O acúmulo de experiência da ZTE no âmbito de precária infraestrutura transformou-se em vantagem comparativa nas exportações, em 1997, para Kenya, Gana, Bangladesh e Paquistão.

Um ano após o anúncio da política industrial, o Ministry of Information Industry (MII), a fusão do MPT e MEI, decretou preferência por equipamentos móveis nacionais. Como o GSM estava sob o comando de multinacionais europeias, tais como Ericsson, Alcatel-Lucent e Nokia, a ZTE optou pelo CDMA da Qualcomm. Em 1998, investiu num centro de pesquisa nos EUA para adaptar a nova versão, CDMA2000, ao mercado interno. No mesmo ano, iniciou a segunda incursão internacional por mercados emergentes: vídeo conferencing (ZTE ZXMVC30000) para Kenya e dual frequency handset (aparelho celular com frequência dual, ou dois chips, ZTE189) para o Paquistão. O contrato paquistanês do aparelho com dois chips permitiu à ZTE, em 2000, ser a primeira produtora mundial de aparelhos celulares CDMA com cartão SIM. No mesmo ano, ao ser designada como fornecedora das redes de CDMA para os dois provedores locais, China Unicom e China Netcom, a ZTE foi anunciada pela Asia Business entre as cinquenta empresas mundiais de melhor desempenho financeiro. Essas previsões foram reforçadas pelo acordo histórico entre ZTE e INTEL para o desenvolvimento conjunto de equipamentos de integração da 3G do CDMA (CDMA2000 1x) com GSM (UMTS). 
O êxito derivado dos investimentos rurais não foi abandonado após a decolagem da ZTE. Em 2004, o governo reforça a orientação no programa Village Access Project (Projeto de Acesso do Vilarejo). A política exigiu das seis operadoras estatais (China Mobile, China Telecom, China Netcom, China Unicom, China Railcom e China Satcom) a cobertura das regiões rurais com serviços básicos de telefonia fixa e banda larga. Por volta de 2007, a cobertura de $99,5 \%$ dos 640,139 Socialist New Villages com infraestrutura fixa, o equivalente a uma densidade de $15 \%$ da população, seria o primeiro passo para estender todos os serviços de Information and Communication Technology (ICT) para as aldeias socialistas. Desde então, as adições mensais da China Mobile, maior provedor mundial de telefonia móvel, se dividem igualmente entre novos clientes urbanos e rurais (XIA; LU, 2008).

Em 2003, a ZTE criou uma coordenação central para suas operações internacionais, a Global Customer Support Center, fechando dois contratos com o principal provedor indiano BSNL e com o governo argelino para instalar a maior rede africana de CDMA. Em 2004, a ZTE se diversifica para o GSM. Constrói a primeira rede 3G (UMTS) africana, licitada pela Tunísia, além de fornecer equipamentos da banda larga fixa (ADSL) para as Olimpíadas de Atenas. Por volta de 2005, a capacidade global da ZTE havia chegado a 100 milhões de linhas. Era, portanto, o maior produtor mundial de equipamentos do CDMA e o quarto do GSM, abrindo caminho para ingressar nos mercados de alto nicho. Para o segundo maior provedor canadense, Telus, entrega, em 2006, equipamentos 3G, seguido por contratos com a France Telecom, Vodafone e Telefónica. Em 2007, a projeção tecnológica da ZTE alcançou novos patamares, ao fornecer equipamentos para WiMax (4G) de Sprint-Nextel e Telefónica, além de introduzir seu sistema de banda larga fixa EPON (atualmente GEPON) sobre fibra óptica. Em 2009, surpreende os produtores europeus, ao exibir equipamentos próprios para o Long Term Evolution (LTE), o 4G derivado do GSM e rival do WiMax, no Mobile World Congress em Barcelona (LAM; SHIU, 2008).

Por volta de 2009, a ZTE detinha contratos com 500 provedores de serviços (equivalente a $51 \%$ do total mundial) distribuídos em 
140 países, cobrindo todo leque de telequipamentos (fixos, móveis e fibra óptica). O sistema chinês de LTE, designado por LTE-TDD (Time Division Duplex) seria uma derivação do TD-SCDMA (Time Division - Synchronous Code Division Multiple Access), criado por Datang Microelectronics Technology Co., Ltd. e registrado na ITU, ao lado da WCDMA e CDMA2000, como o terceiro tronco de 3G. Fundada em 1996, a Datang é a nova razão social do antigo Information and Communications (IC) Design Center da China Academy of Telecommunications Technology, braço de pesquisa do MPT. Para poder atender tanto às dispersas áreas rurais COmo aos densos bairros populares metropolitanos, o flexível TDSCDMA compatibiliza as bandas largas móvel e fixa. Com vistas a reforçar as pesquisas da sua versão da LTE, deslocou, em 2009, 4 mil dos seus pesquisadores para seus laboratórios em Xian, Shenzhen, Nanjing e Shanghai, dedicados exclusivamente ao seu aperfeiçoamento, absorvendo 40\% dos gastos em P\&D de telefonia celular.

Consequentemente, em 2010, firmou cinco contratos para equipamentos de LTE-TDD com a China Mobile, com a portuguesa Sonaecom (LTE-FDD, padrão europeu), e com o Commnet, provedor regional de LTE nos Estados de Arizona, Novo México e Utah. A habilidade da ZTE de produzir equipamentos flexíveis, derivada da sua longa experiência de compatibilização sistêmica nas regiões rurais, levou ao lançamento do primeiro sistema de transição entre 3G e 4G (LTE DC-HSPA+), introduzido no final de 2010 em Hong Kong e pela Hutchinson na Áustria, Optimus em Portugal e KPN na Holanda, esta em fevereiro de 2011.

Novamente, durante o Mobile World Congress em Barcelona, em março de 2011, a ZTE revelou seu refinamento tecnológico ao demonstrar um bandwidth de 1gbits/s da banda larga móvel. Em 2011, ainda instala sete redes comerciais de LTE nos EUA e testa outras cinquenta redes na Europa, Oriente Médio e Ásia. No mesmo ano, a ZTE assumiu a quarta posição na produção de telequipamentos, em substituição à Alcatel-Lucent, tornando-se o maior produtor mundial de CDMA, terceiro GSM e primeiro da fibra óptica. Para sustentar sua posição, financiou uma rede de laboratórios em quinze países, empregando 30 mil pesquisadores e produzindo 
uma média de 1.900 patentes anuais, a segunda colocação mundial. O foco atual da empresa é nova fronteira tecnológica de M2M, cloud computing, Tri-Network computing e Smart pipe.

Apesar dos avanços do LTE-TDD pela ZTE, O Ministry of Information Technology (MIIT) insistiu na diversificação tecnológica, convidando, no início de 2010, diversas multinacionais para instalar redes experimentais de LTE-FDD para a China Mobile em seis cidades (Shanghai, Hangzhou, Nanjing, Guangzhou, Shenzhen e Xiamen). Em janeiro de 2010, Alcatel-Lucent, Nokia e Siemens realizaram testes em Shanghai e em Hangzhou, respectivamente. A First International Telecom (FITEL), provedor de 4G, iniciou em setembro de 2010 testes de bandwidth em Tayoun, como pré-requisito do National Communications Commission (NCC), para aprovar sua migração do Wimax para LTE-TDD.

Na telefonia convencional e banda larga fixa, suas arenas tradicionais, a ZTE desponta como a líder mundial em fibra óptica. Em setembro de 2009, seu sistema híbrido EPON-Lan evoluiu para 10G EPON, padronizado pelo IEEE (802.3av). Como a ZTE foi a única empresa a produzir, em 2008, equipamentos da NG-PON (Next Generation-PON) (ZXA 10C300), com capacidade de integrar os três sistemas de fibra óptica, EPON, GPON e P2P, foi escalonada pelo ITU para elaborar seu padrão mundial, ITU-TG.987, a ser adotado em 2011. A reafirmação da liderança tecnológica na fibra óptica ocorreu em abril de 2011, quando a ZTE registrou uma transmissão de 10 terabits/s numa conexão sobre um cabo com extensão de $640 \mathrm{~km}$, a maior bandwidth já alcançada. Por volta de 2011, a ZTE passou a ser o único fornecedor mundial de equipamentos da FTTx para compradores de redes de alta velocidade na faixa de $400 \mathrm{Gbits} / \mathrm{s}$ - 1 Tbits/s. Os saltos tecnológicos na fibra óptica são associados à decisão governamental de expandir as infovias regionais pela estatal China Telecom, tendo como meta triplicar a clientela, em 2011, para 30 milhões (já alcançada) e 100 milhões até 2015 (IDATE, 2010). Em junho de 2011, o número de chineses ligados numa rede de fibra óptica superou a soma mundial de usuários, incluindo os países membros da Organization for Economic Cooperation and Development (OECD) (OECD, 2009).

Os mesmos saltos tecnológicos e produtivos da estatal ZTE se replicaram no grupo privado Huawei, considerado a nova potência 
mundial de telequipamentos, reforçando a tese de intervenção governamental como principal motriz do êxito chinês. Ren Zengfei, o mais celebrado e misterioso empresário chinês da atualidade, fundou a Huawei em 1988 como uma pequena importadora de terminais de comutação. Filho de um cozinheiro e uma professora de segundo grau, o engenheiro de telecomunicações pela Universidade Militar de Engenharia Civil e Arquitetura da Chongqing começou sua carreira na divisão rural do Instituto Tecnológico do exército chinês (PLA, People's Liberation Army). Reconhecido por mérito, foi designado chefe da delegação militar para a Conferência Nacional de Ciência, em 1978, e para o $12^{\circ}$ Congresso Nacional do Partido Comunista Chinês. Em 1982, desligou-se do exército para abrir um negócio próprio de importações eletrônicas.

Em 1990, a Huawei passou de importadora para produtora de equipamentos. Diferentemente da estatal ZTE, apoiada por centros de pesquisas oficiais e planos governamentais, a particular Huawei especializou-se em reverse engineering, com produção destinada a pequenos municípios rurais. Sua reputação inicial de desrespeitar patentes com práticas de adaptação e incrementação perdurou até 2002, quando a Huawei passou a ser Original Equipment Manufacturer (OEM), tornando-se o maior produtor mundial de equipamentos para telefonia móvel. A transição para a produção original não seria possível sem vultosos investimentos em recursos humanos de alta qualidade, assegurados por compras governamentais para as redes rurais. Zenghfei, em média, destinava,desde a fase industrial da Huawei, 10\% dos seus retornos às equipes de adaptação, chegando à soma de US $\$ 3$ bilhões em 2010. Em 1993, foi fechado o primeiro contrato para uma rede rural, por intermédio do exército, para substituir as ultrapassadas centrais de comutação da Fujitsu, pertencentes à prefeitura de Yiwu da província de Zhejiang. Outras prefeituras se seguiram. Em 1994, a Huawei já era a segunda empresa chinesa fornecedora oficial das redes rurais para os provedores estatais. Oito anos após o início da produção industrial, a Huawei, com 20\% do mercado nacional, já era a segunda produtora de equipamentos de comutação fixa, seguindo a multinacional Shanghai Bell (22\%).

A estratégia territorialista da Huawei refletia o treinamento militar do seu fundador. Cercar e dominar mercados de forma 
incremental foi ideia posta em prática em Sichuan e Shanghai. Na primeira, uma ampla região com presença tradicional da Shanghai Bell iniciou um projeto de atualização da sua rede fixa. Para conquistar contratos locais, a Huawei lançava uma proposta audaciosa de fornecimento gratuito de equipamentos como parte do custo da instalação e manutenção das redes. Para cada região, Zenghfei fundou um comando autônomo (Shanghai Huawei, Chengdu Huawei e Shengyang Huawei) com a finalidade de negociar as demandas dos governos municipais e a subcontratação de fornecedores e empreiteiras locais. Considerada uma estratégia suicida por Shanghai Bell, joint venture da Alcatel, esta optou por não reagir, prevendo o esgotamento financeiro da Huawei. Como evidenciado, a estratégia territorialista da Huawei obteve êxito. Após os primeiros contratos, outras prefeituras aderiram à oferta. Apesar das alegações de negociações clandestinas, as redes da Huawei mostravam qualidade e baixo custo. Por volta de 2002, a Huawei substituiu a joint venture multinacional como maior fornecedora de equipamentos na região, com 70\% do mercado local.

Em 2001, a Huawei desloca sua atenção para a telefonia móvel, um nicho exclusivo da Shanghai Bell (Alcatel) e da BISC (Siemens). Como parte do acordo do ingresso da China na OMC, os dois investidores externos receberam permissão de assumir o controle acionário dos dois joint ventures, e, assim, fortaleciam mais ainda sua presença no mercado chinês com novos investimentos. Ao perceber sua inabilidade de ingressar no nicho dos maiores produtores mundiais de equipamentos, a Huawei dirige sua produção para roteadores (routers) de especialidade de Cisco. Apoiada por compras governamentais, a Huawei diminuiu a fatia de mercado de Cisco de 80\% para 69\% em 2001, e assume o control majoritário do mercado interno em 2004 (MU; LEE, 2005).

Não obstante as diferenças na razão social, as estratégias empresariais dos dois produtores se inseriram na política oficial de igualar as condições de acesso ao mercado interno entre as metrópoles e o campo; construir infovias para interligar todas as regiões; adaptar e comandar tecnologia de ponta mediante experimentação no mercado interno e aumentar a fatia das exportações. Os recursos financeiros necessários para colocar em prática a 
ambiciosa meta de construir o setor mais avançado da atualidade vieram das compras governamentais.

Neste âmbito, a centralizada governança corporativa dos dois produtores facilitou a aglutinação e flexibilização de recursos financeiros, tecnológicos e humanos. A despeito de a ZTE ser empresa estatal, seu estatuto admite a captação de crédito no mercado financeiro, venda de ações minoritárias para particulares e alianças empresariais locais e internacionais. Desde 1988, a privada Huawei, segundo maior produtor mundial de telequipamentos, com faturamento anual de US\$ 30 bilhões, permanece uma sociedade limitada. Seu fundador, Ren Zengfei, no entanto, detém apenas 1,42\% das suas ações, enquanto os outros 98,56\% são controlados pelos empregados por meio do sindicato, Union of Shenzhen Huawei Investment Holdings Co Ltd. Dos seus 95 mil empregados, apenas 61 mil são acionistas uma vez que é vedado a funcionários de outras nacionalidades a aquisição de ações votantes. Os 33 membros da diretoria do sindicato são eleitos pelos empregados e destes são selecionados nove dos dez diretores da Huawei, além de Ren Zengfei. O faturamento anual é revertido em novas ações, distribuídas junto aos empregados, de acordo com a escala salarial e avaliação de desempenho. Como mais da metade dos empregados se dedica à $\mathrm{P} \& \mathrm{D}$, o mecanismo de remuneração acionária garante a elevação de produtividade, busca de treinamento, zelo pela qualidade de produtos e resguardo da reputação da marca (branding), evitando a abertura do capital social aos investidores financeiros. Em geral, a governança corporativa das duas empresas prioriza a produtividade industrial em detrimento da especulação financeira das multinacionais.

Em 2011, a Huawei transformou-se na segunda maior produtora mundial de equipamentos de rede móvel, com 15,7\% do total, equivalente a US\$12,34 bilhões, perdendo apenas 19,6\% da Ericsson. No entanto, as taxas de crescimento revelam uma desenfreada subida dos dois produtores chineses com acesso a 71\% do mercado interno, adições anuais internas de $20 \%$ e externas de 31\%. A força da Huawei evidenciou-se em abril de 2011, quando ofereceu uma irrecusável proposta para atualizar a rede móvel da Oi. Com uma linha de crédito de US\$ 30 bilhões garantida pela 
China Development Bank, Huawei ofereceu à Oi equipamentos com um período de graça de dois anos, além de uma taxa de financiamento de $4 \%$ anuais, contra $6 \%$ oferecida por JP Morgan na proposta da Ericsson.

Contudo, o êxito da política industrial dependeu da estruturação do maior e mais dinâmico mercado mundial de telecomunicações organizado em torno de três dos maiores provedores mundiais. Fatores internos, tais como compras governamentais, CObertura infraestrutural e diversificação tecnológica, asseguraram uma inesgotável fonte de investimentos, crédito para exportação e ilimitado ambiente de experimentação e inovação, impulsionando o setor chinês à liderança mundial.

\section{FORMAR PROVEDORES ESTATAIS DE SERVIÇOS PARA O SÉCULO XXI}

A organização do modelo de serviços ocorreu em dois intervalos. Durante o primeiro, coincidente com as negociações do ingresso da China na Organização Mundial do Comércio (OMC), o governo decretou a autonomização das empresas estatais, estabelecendo dois objetivos - ampliar a densidade telefônica e diversificar a matriz tecnológica interna. Novamente, os investimentos dos provedores estatais na infraestrutura rural induziram a transferência de tecnologia e sua domesticação por produtores de telequipamentos. Assegurada ampla cobertura regional e comandados os diversos gêneros tecnológicos, na segunda fase, o governo fortaleceu as instituições de planejamento setorial e incentivou as fusões entre os provedores estatais.

Os primeiros passos começaram entre julho de 1994 e março de 1998, em antecipação ao ingresso da China na OMC, formalizado em novembro de 1999. Suas três características são: 1) controle majoritário nacional, tanto da infraestrutura como dos serviços, porém com abertura de atividades adicionadas (internet, paging etc.) ao capital externo; 2) regionalização dos serviços fixos Como meio de estender a infraestrutura e universalizar os serviços básicos em todo o território chinês; e 3) distribuição de empresas por sistema tecnológico da telefonia móvel com o propósito de disponibilizar o maior conjunto de opções disponíveis no mercado internacional. 
A opção pela regionalização infraestrutural e diversificação tecnológica teria motivos defensivos e desenvolvimentistas ao mesmo tempo. Primeiro, um monopólio nacional poderia bloquear a universalização, uma vez que os custos elevados de estender a rede básica canalizariam investimentos às regiões prósperas e de maior densidade populacional, marginalizando as regiões periféricas, as camadas sociais de baixa renda e os municípios rurais. Segundo, como a China pleiteava seu ingresso na Organização Mundial do Comércio, seria inevitável a abertura das bolsas de valores aos investidores internacionais. Um monopólio nacional seria bem mais vulnerável à captura por investidores financeiros do que um segmentado mercado interno. Terceiro, uma empresa monopolista teria dificuldade na capitalização financeira por morosidade de decisões e temores de ineficiência no desempenho.

Em 1994, os dois maiores provedores, a China Telecom e a China Unicom, surgiram de departamentos governamentais. O primeiro, especializado em telefonia fixa, aglutinava as redes provinciais e municipais do General Directory of Telecommunications (GDT) - Diretoria Geral das Telecomunicações, responsável pela operação de $98 \%$ dos fluxos eletrônicos nacionais. A segunda, de vocação móvel, herdou treze estatais e as redes de comunicações administrativas dos Ministry of Electronics Industry (MEI), Ministry of Railway e Ministry of Electrical Energy (MEE).

A estruturação dos dois primeiros provedores nacionais foi seguida por uma fusão do Ministry of Posts and Telecommunications (MPT) com o Ministry of Electronics Industry para formar o Ministry of Information Industry (MII). A designação do novo superministério reafirmava o princípio, original de 1949, da integração entre serviços e produção industrial. A unificação dos laboratórios; recursos humanos e gerenciais; e orçamentos dos dois históricos ministérios garantiram uma capacidade de direção do setor mais visado pelas multinacionais.

Em outubro de 1999, um mês antes da assinatura do acordo com a OMC, o governo iniciou a multiplicação e o fortalecimento das empresas nacionais em antecipação à abertura do mercado. A China Unicom recebeu a Guoxin, a rentável divisão de paging, da China Telecom, e lançou uma oferta pública de ações na bolsa 
de valores de Hong Kong, captando US\$ 4,9 bilhões. Em maio de 2000, a China Telecom perde mais três divisões: a de celular para formar a China Mobile (GSM), atualmente maior provedor mundial; a da banda larga fixa (ADSL), dando origem à China Netcom; e a de satélites, em novembro de 2000, para lançar a China Satcom.

O terceiro tronco empresarial se formou em 2001, em torno das redes de fibra óptica do Jetons, a maior ferrovia chinesa, e da rede do Ministry of Railways (Ministério das Ferrovias), originando empresas especializadas em transmissão de dados por fibra óptica, a China Railcom (mudada para China Tietong em 2004) e a Jitong. A China Railcom operava a maior rede de fibra óptica na Ásia, interligando Beijing, Shanghai e Guangzhou, e cobrindo as 500 maiores cidades do centro e do leste. Por volta de dezembro de 2001, ao terminar a estruturação de serviços, sete empresas cobriam todo o território chinês com um amplo leque tecnológico: telefonia fixa (China Telecommunications), telefonia móvel (China Mobile com GSM e China Unicom com CDMA), ADSL (China Netcom), fibra óptica (China Railcom e Jitong) e satélite (China Satellite).

O plano bianual (2002-2003) aprofunda mais ainda a diversidade tecnológica. Em maio de 2002, a China Telecom perde dez redes provinciais, entre estas, a Beijing para a China Netcom, mantendo 21 províncias do sul, o equivalente a 60\% da população. No mesmo ano, a China Netcom incorpora a Jitong para formar uma rede integrada de fibra óptica com a telefonia fixa. A diversificação da telefonia móvel por sistema tecnológico começou logo após o anúncio da fusão ministerial, quando o novo MII reservou o GSM para o maior provedor, a China Mobile, a China Unicom se especializou na CDMA da Qualcomm, além de uma oferta limitada do GSM. Ainda, o MII demandou a oferta, pelas duas estatais, do sistema japonês Personal Digital Celular (PDC) nas regiões rurais pela metade dos custos dos sistemas convencionais (LOO, 2004).

Em maio de 2008, inicia-se uma inversão da primeira fase, marcada pela transferência e diversificação tecnológica. O MIIT, substituto do MII, aglutina mais recursos empresariais, tecnológicos e financeiros para garantir a autonomia tecnológica e industrial. Além de a jurisdição do novo ministério abranger toda a indústria hi-tech, com ênfase especial nos telequipamentos, 
assumiu a missão de construir as infovias de interligação interna, a regulação das comunicações, financiamento de aplicações tecnológicas e segurança nacional de comunicações eletrônicas. A reestruturação governamental foi complementada por um período de fusões empresariais entre provedores de serviços. Neste âmbito, a China Satcom foi absorvida pela China Telecom e transferida para a China Airspace Technology Corporation em abril de 2009. Em 2008, a China Tietong (antiga Railcom) passou ao controle da China Mobile e em outubro de 2008, a China Unicom incorpora a China Netcom. Terminada a reestruturação, surgiram três dos maiores provedores mundiais de serviços, todos de controle acionário governamental: a China Mobile, maior grupo mundial de telefonia móvel, com 600 milhões de clientes, a China Unicom, $11^{\circ}$ grupo, com 164 milhões de usuários, e a China Telecom, $21^{\circ}$ grupo mundial e 94 milhões de assinantes. Após duas décadas de uma planejada intervenção, o Estado chinês conseguiu estruturar o maior e mais dinâmico mercado mundial de telecomunicações, sustentando um desenvolvido parque industrial e um adiantado comando tecnológico.

\section{CONCLUSÃO}

O salto qualitativo chinês, revelado em estudo de caso das telecomunicações, foi uma obra de conscientes decisões políticas por instituições governamentais fundadas pela revolução de 1949. A inclusão social, por via da igualdade de condições entre o campo e a cidade, determinou a finalidade das intervenções públicas. Na década de 1980, mudaram seus instrumentos, porém permaneceu seu princípio de direcionar os recursos públicos, sejam financeiros, institucionais, empresariais ou tecnológicos para assegurar a todos os cidadãos as mesmas condições e expectativas de vida.

Essa política centrada na inclusão diferencia-se dos caminhos percorridos pelos países desenvolvidos? Certamente que não. Durante um século, a prosperidade do capitalismo adiantado dependia das políticas de universalização dos direitos. O acordo histórico de Woodrow Wilson com AT\&T, reforçado por Franklin Roosevelt, na Communications Act, de 1934, que deu nascimento ao poderoso Federal Communications Commission (FCC), 
estabeleceu o princípio da universalização como razão de existência da mais antiga empresa estadunidense. Durante um século, a AT\&T administrou a maior e mais eficiente infraestrutura mundial de telecomunicações sustentada pelo Laboratório Bell, celeiro de Prêmios Nobel de Física. Apesar da sua razão social privada, a AT\&T aceitava ser um instrumento de igualdade de condições entre os cidadãos dos EUA estendendo suas redes das grandes metrópoles aos pequenos condados rurais.

Missão semelhante havia sido acampada pela Nokia e Ericsson, em 1969, como proponentes do Nordic Teleconference. Dotar as regiões rurais com uma infraestrutura e serviços equivalentes aos mais adiantados centros urbanos nórdicos era tida como uma das obras-primas do Welfare State. Ao assumir a missão de ser um instrumento de inclusão, a Nokia, empresa privada de beneficiamento de madeira, nascida no campo finlandês, alcançou em menos de uma década a liderança mundial da telefonia celular.

Ao longo de um século, as políticas de inclusão diferenciavam o capitalismo desenvolvido com suas instituições de bem-estar social, impecáveis infraestruturas, elevados salários, facilidade de acesso e as mais baixas tarifas mundiais, das desigualdades de acesso que travavam o desenvolvimento do capitalismo subdesenvolvido. Na década de 1980, os dois passaram a convergir quando as metas de inclusão foram substituídas pela competitividade. Consequentemente, as políticas públicas submetiam os mercados internos às prioridades e escolhas tecnológicas dos interesses privados. Na década de 1990, à medida em que a política chinesa demandava dos seus provedores estatais a cobertura de mercados rurais, a adaptação de complexas tecnologias às demandas populares e a provisão de serviços para os estratos de baixa renda, os governos dos países desenvolvidos aceitavam enquadrar seus cidadãos às prioridades financeiras e escolhas tecnológicas de grupos empresariais. Com a experimentação, a adaptação e a inovação tecnológica direcionadas à demanda popular, as empresas chinesas expandiam seu raio de atuação nos mercados emergentes, enquanto os conglomerados desenvolvidos restringiam seu mercado aos estratos de elevada renda, transitando da produção própria à global outsourcing (subcontratação global) e assumindo as estratégias financeiras como nova vocação. 
No caso chinês, resta saber se os avanços da igualdade de condição, posta em prática na vida material, se estenderão aos direitos políticos e à liberdade de expressão. A despeito de os avanços econômicos, científicos e tecnológicos serem indispensáveis, separados da livre associação política isto é insuficiente para sustentar a equidade inclusiva como doutrina do Estado. Afinal, a mais humana das condições continua sendo a necessidade de participar e opinar sobre os destinos da nação, assegurando que as conquistadas igualdades de condições não sucumbam às finalidades privadas.

\section{REFERÊNCIAS}

GEREFFI, Gary. Development models and industrial upgrading in China and Mexico. European Sociological Review, v. 25, n., 1, p. 37-51, 2009.

HARVEY, David. A brief history of neo-liberalism. Oxford: Oxford University Press, 2005.

IDATE. FTTX 2010: markets, facts and trends. Montpellier, 2010.

ILLE, Francis R.; CHAILAN, Claude. Improving global competitiveness with branding strategy: cases of chinese and emerging countries firms. Journal of Technology Management in China, v. 6, n. 1, p. 84-96, 2011.

JOHNSON, Chalmers. MITI and the japanese miracle. Stanford: Stanford University Press, 1982.

. Political institutions and economic performance:

the government-business relationship in Japan, South Korea, and Taiwan. In: DEYO, Frederic (Ed.). The political economy of the new Asian industrialism. Ithaca: Cornell University Press, 1987.

LAM, Pun-Lee; SHIU, Alice. Productivity analysis of the telecommunications sector in China. Telecommunciations Policy, v. 32, n. 8, p. 559-573, 2008.

LOO, Becky. Telecommunications reform in China: towards and analytical framework. Telecommunciations Policy, v. 28, n. 9-10, p. 697-714, 2004. 
MU, Qing; LEE, Keun. Knowledge diffusion, market segmentation and technological catch-up: the case of telecommunications industry in China. Research Policy, v. 34, n. 6, p. 759-783, 2005. OECD information technology outlook. Paris, 2008. (Information and Communication Technologies).

OECD internet access for development. Paris, 2009. (Information and Communication Technologies).

RODRIK, Dani. Making room for China in the world economy.

American Economic Review, v. 100, n. 2, p. 89-93, 2010.

WANG, Huijiong; HONG, Yan. China: technology development and management in the context of economic reform and opening. Journal of Technology Management in China, v. 4, n. 1, p. 4-25, 2009.

XIA, Jun; LU, Ting-Jie. Bridging the digital divide for rural communities: the case of China. Telecommunications Policy, v. 32, n. 9-10, p. 686-696, 2008.

XIE, Wei; WHITE, Steven. From imitation to creation: the critical yet uncertain transition for Chinese firms. Journal of Technology Management in China, v. 1, n. 3, p. 229-242, 2006.

YU, Zhou; YIFEI, Suny, WEIZ, Dennis; LIN, George. De-centering "spatial fix" - patterns of territorialization and regional technological dynamism of ICT hubs in China. Journal of Economic Geography, v. 11, n. 1, p. 119-150, 2011. ZTE TECHNOLOGIES, v. 13, n. 6, issue 137, Dec. 2011. Availabre from: <http://wwwen.zte.com.cn/endata/magazine/ ztetechnologies/2011/No6/>. 